\title{
A technique for defogging intra tympanic mirrors
}

\author{
Jaiganesh Manikavasagam • \\ Baskaran Ranganathan $\cdot$ Jayanth Dugar
}

Received: 17 May 2009 / Accepted: 4 June 2009 / Published online: 15 July 2009

(C) Springer-Verlag 2009

The sinus tympani in the middle ear have been the focus of clinical interest because of its tendency to be invaded by a cholesteatoma. Due to its visual obscurity, and the lack of a straightforward surgical approach, it can be difficult to address [1]. Most residual cholesteatoma present in the sinus tympani [2]. It can be visualised by intra tympanic mirrors, Oto-endoscopes, or with techniques like, removal of the lateral lip of bone and tilting the patient's head and/or microscope. Removal of the disease from sinus tympani is also influenced by surgical approaches, which include the anterior to posterior and the retro facial approach [3].

While using the intra tympanic mirror to visualise the sinus tympani, the mirror tends to fogs up. To prevent this from occurring, anti-fogging solutions or warming up the mirror are techniques that are readily used. We describe the following simple method to prevent fogging. A microsuction tip could be kept intermittently 2-3 mm away from the mirror. The turbulence of the air flow generated by the suction would prevent the fogging. Microsuction is readily available on the operating table (Fig. 1).

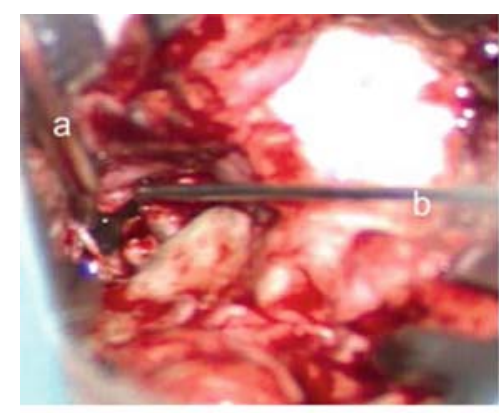

i

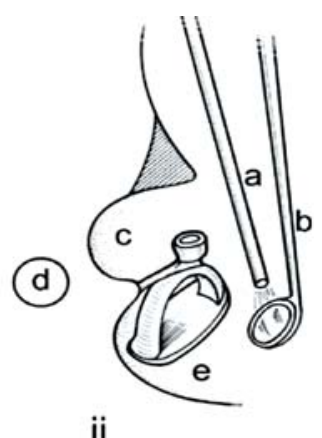

ii
Fig. 1 i Sinus tympani visualised with intra tympanic mirror (microscopic view). ii Diagram to explain $a$ Zoellner microsuction, $b$ intra tympanic mirror, $c$ facial recess, $d$ facial nerve, $e$ sinus tympani area

\section{References}

1. Baki M, El Dine MB, El Saiid I, Bakry M (2002) Sinus tympani endoscopic anatomy. Otolaryngol Head Neck Surg 127:158-162. doi: $10.1067 / \mathrm{mhn} .2002 .127588$

2. Sheehy JL, Brachmann DE, Graham MD (1977) Choleasteatoma surgery: residual \& recurrent disease: a review of 1024 cases. Ann Otol Rhinol Laryngol 86:451-462

3. De Abreu C, Eduardo C, Cruz OLM (2007) Surgical anatomy of anterior and retro facial approaches to sinus tympani. Otol Neurotol 28:682-684 